\title{
O TRABALHO DO ENFERMEIRO DE CENTRO CIRÚRGICO NO BRASIL (DÉCADA DE 80) *
}

\author{
Brigitta Elza Pfeiffer Castellanos**
}

CASTELLANOS, B.E.P. O trabalho do enfermeiro de centro cirúrgico no Brasil (década de 80). Rev. Esc. Enf. USP, v. 25, n. 2, p. 177-94, ago. 1991.

A partir da visão materialista-histórico e dialética do trabalho da Enfermagem como uma prática social inserida no modo de produção capitalista brasileiro desta década de 80, este estudo, pela decomposição do trabalho do enfermeiro de centro cirúrgico em seus três elementos essenciais procurou apontar para a necessidade da compreensão não soinente destes três elementos mas, principalmente, para o entendimento de suas relações super-estruturais mediadas pelo modo de produção brasileiro no sentido de, por meio desta praxis reflexiva, buscar uma sintese, entre o que tenho (o que è o trabalho do enfermeiro de centro cirúrgico) e o que quero, sintese esta que possibilite uma nova prática.

UNITERMOS: Enfermagem em centro cirúrgico. Exercicio da enfermagem.

\section{PARTE 1 - DO SIGNIFICADO}

A modalidade de estudo sobre o exercício profissional do enfermeiro (trabalho, papel, função, atividades, etc.) tem sido, com raras exceções, a "reacional", diagnosticanço os principais "disfunções" do perfil do enfermeiro, através do levantamento das atividades realizadas, por meio de questionários respondidos por profissionais ou de observações diretas dos pesquisadores.

A caracterização do exercício profissional do enfermeiro pode ser desenvolvida a partir de "modelos teóricos de papel", numa abordagem intradisciplinar ou multidisciplinar, sob o ponto de vista intrapessoal e interpessoal, bem como do relacionamento do Homem com o seu meio físico-sócio-cultural.

A análise do "papel" do enfermeiro no Brasil tem sido apresentada de várias maneiras, mas usualmente têm-se limitado à descrição das

\footnotetext{
* Trabalho apresentado como tema oficial da II JORNADA DE ENFERMAGEM DE CENTRO CIRÚRgICO DO ESTADO DE SÃO PAULO - julho, 04 a 30 de julho de 1988 e baseado na tese de doutorado do autor.

* Prof. Assistente Doutor do Departamento de Enfermagem em Saúde Coletiva da Escola de Enfermagem da USP.
} 
açōes que esse profissional executa (ou deve executar). Estas descrições evidenciam o sinal marcante de uma postura positivista resultante da hegemonia do referencial idealista técnico-pragmático no marco conceitual da Enfermagem enquanto assistência, pesquisa e ensino, que se impregna nas abordagens "quantitativas" e "atomistas" (redução da totalidade a elementos para, a partir deles, construir o social) de análise do exercício, que tomaram de empréstimo os pressupostos das ciências naturais, privilegiando assim, na pesquisa, os modelos mecanicistas de produção de conhecimento.

Nesta modalidade funcionalista do estudo do exercício profissional, merece ser evidenciado que, com raras exceções, a "população pesquisada" (enfermeiros, auxiliares e atendentes de enfermagem e/ou pacientes) percebe-se fornecendo dados que respondem a planos com propósitos pouco ou nada conhecidos e cujos produtos ou não lhes são dados a conhecer ou, quando o são, são percebidos como ameaçadores e/ou deixam dúvidas, constrangimentos ou ceticismo. Por outro lado, esta situação promove não só dificuldades de aplicação do resultado dessas pesquisas como a impossibilidade de haver qualquer perspectiva de transformação da prática profissional.

A partir deste final de década, apesar de ainda com pequena freqüência, o exercício profissional tem siào enfocado também, na sua estrutura $1,6,12,13,17,10$, e não somente em relação ao seu conteúdo, o que traz várias implicações no que diz respeito à atuação do enfermeiro como um dos agentes de transformação social.

Tendo como base referencial estas críticas metodológicas, acredito que o estudo do exercício profissional do enfermeiro de Centro Cirúrgico (C.C.) deve dirigir-se para a busca de formas que permitam abordar suas "atividades" numa perspectiva conceitual de assistência de enfermagem como "praxis", ou seja, como uma "atitude transformadora da natureza e ca sociedade ajustada a objetivos", na qual o "subjetivo se integra no objetivo" (isto é, "imprime o cunho das finalidades do agente") e não numa concepção de conjunto de ações, de atos desarticulados ou justapostos casualmente destinados a satisfazer interesses pragmáticos do enfermeiro C.C. na sua intervenção no processo saúde-doença do cliente durante o periodo perioperatório.

Do ponto de vista do Materialismo Histórico, o Homem se diferencia do Animal desde o momento em que começa a produzir seus meios de vida. O que o Homem é, coincide, portanto, com a sua produção, tanto com o que produz, como com o modo pelo qual produz. Isto significa dizer que o Homem é determinado pelas relações sociais e, em primeiro lugar, pelas relações sociais de produção que determinam sua individualidade em determinadas condições.

Assim sendo, a prática do enfermeiro é uma manifestação social e esta prática, enquanto processo de transformação de uma matéria-prima (objeto de trabalho do enfermeiro) segundo intencionalidades (objetivos, finalidades) é o seu TRABALHO. 

OBJETIVA DO TRABALHO DO ENFERMEIRO DE CENTRO CIRÚRGICO BRASILEIRO

Há necessariamente que distinguir neste processo de trabalho os seus três elementos essenciais: a) a atividade humana, adequada a um fim, realizada e utilizada no processo - "o trabalho e a força de trabalho"; b) a matéria a que se aplica o trabalho - "o objeto de trabalho" e c) os meios com os quais se trabalha - "o instrumental de trabalho".

PRIMEIRO ELEMENTO DO TRABALHO DO ENFERMEIRO DE CENTRO CIRÚRGICO: o trabalho e a força de trabalho do enfermeiro (e da Enfermagem).

A transformação dos níveis de saúde de uma Sociedade não depende, indubitavelmente, exclusivamente das ações do "Setor Saúde", mas sim do grau de desenvolvimento social para atender às suas necessidades globais; assim sendo, o perfil epidemiológico da população brasileira, reflete as nossas estruturas: econômica e jurídico-política e ideológica.

A par de todas as intencionalidades manifestas nos diversos documentos oficiais, desde os das "Conferências Nacionais de Saúde", dos "Planos" e "Sistemas de Assistência", até os da atual "Reforma Sanitária", qualquer tipo de análise evidencia que nossas instituições de prestação de serviços de saúde, têm tido muita dificuldade $\mathrm{em}$ implementar concretamente as mudanças apontadas. O modelo de assistência à saúde vigente, continua sendo o "modelo médico-burocrático", o qual não tem atendido às necessidades da totalidade da população brasileira, uma vez que, por ser biologilizante, a-histórico, pragmático, autoritário, individualista e curativo supõe de fato, por um lado, 0 aumento da medicalização e do uso de equipamentos cada vez mais sofisticados, e por outro, coloca os fatores causais e terapêticos na pessoa individualmente, ou, quando muito, em seu "ambiente natural", no qual os determinantes histórico-sociais do processo saúde-doença estão ausentes ou muito secundariamente tomados em consideração, e onde o "sujeito" da atenção é sempre passivo, não participativo.

Às criticas a modelo (ao qual a Enfermagem não se tem contraposto, mas sim tem se adaptado em sua articulação com as instâncias super-estruturais) é interessante evidenciar o alinhamento, linear e mecanicista, da nossa profissão com a prática médica em relação a uma orientação à classe dominante da sociedade brasileira. Esta relação é encoberta quando se postulam abordagens (científicas e técnicas) falsamente "neutras" e evidenciadas pela não consideração da vinculação de classe na determinação do perfil epidemiológico. E, assim sendo, com intervenções que, apesar de diminuirem problemas que se manifestam na pessoa como processo individual, têm aplicações muito limitadas e elitizantes enquanto abordagens intensivamente predominantes da dimensão biológica de tais problemas e que não relacionam os processos 
estruturais da sociedade que permitem aclarar o aparecimento de condiçōes de vida diferenciadas, nem tampouco relacionam os perfis de produção e consumo (reprodução social) das diferentes classes sociais com os correspondentes bens ou valores de uso (potencialidades) de saúde e sobrevivência, assim como os riscos (contravalores) de adoecer e morrer ${ }^{2}$, permanecendo, desse modo, oculta a existência de um perfil epidemiológico, uma taxa de mortalidade e de esperança de vida diferencial em termos de classe, estrato de classe e setores ocupacionais ${ }^{24}$.

A prestação de assistência à saúde no Brasil (melhor dizendo, da "assistência médica"), processa-se com a intervenção de diferentes categorias profissionais, existindo distorções na alocação destas categorias, como por exemplo, a existência de pequena disponibilidade de profissionais no total, de uma concentração regional, da escassez de enfermeiros em relação no número de médicos e atendentes de enfermagem, e assim por diante.

Dispomos de apenas 20 enfermeiros para cada 100 médicos quando, em outros países, essa proporção é inversa: EEUU-380 enfermeiros para 100 médicos; Colômbia: 157,6/100 e Inglaterra 250/100 (dados para 1982). Destaca-se ainda que esta relação se modifica em relação ao "serviço público" - 26, 2 enfermeiros/100 médicos - e ao "setor privado" - 10,6: 100 - para cada 100 leitos hospitalares ${ }^{17}$.

A Enfermagem como profissão da "área da Saúde" é, certamente, co-responsável no objetivo nacional da transformação do perfil epidemiológico da população brasileira e, não obstante a manifestação de intenções nesse sentido, a nível das instâncias intra e extra-categoria, ela se encontra em situação crítica numa perspectiva quantitativa de seus recursos humanos, e principalmente, numa perspectiva de qualidade destes recursos como instrumentos do alcance dessa meta.

Como categoria social, a Enfermagem desenvolve concretamente e legitimamente suas funções com a participação de pessoal diversificado em graus de escolaridade prévia e na formação específica, representando cerca de $53,42 \%$ dos trabalhadores de saúde no país $(304,287)^{15}$. Nesta força de trabalho, os enfermeiros representam, para o Brasil, $8,5 \%$, os técnicos de enfermagem $6,6 \%$, os auxiliares de enfermagem $21,1 \%$ e os atendentes $63,8 \%$, senảo que para São Paulo esta distribuição mantém-se similar. Quanto à sua alocação, a força de trabalho da Enfermagem no Brasil está mais concentrada nos estabelecimentos hospitalares $(70,4 \%)$, sendo que em São Paulo constata-se a maior penetração da iniciativa privada com a conseqüente maior proporção de leitos e a mais alta proporção de enfermeiros no setor privado. Apenas 12,3\% dos hospitais e $19,6 \%$ dos leitos existentes no país não são privados, o que denota que a assistência hospitalar pública alcança a menor parcela da população. Para o Brasil, nos hospitais públicos existem $44,4 \%$ de atendentes, $29,7 \%$ de auxiliares, $13,8 \%$ de técnicos de enfermagem e $12,0 \%$ de enfermeiros, enquanto que no setor privado, a proporção de atendentes sobe para $72,6 \%$ e a de auxiliares, técnicos e enfermeiros cai para $18,9 \%, 4,3 \%$ e $4,1 \%$, respectivamente ${ }^{15}$. 
Em relação à força de trabalho da Enfermagem em C.C., a situação é bastante ímpar, uma vez que nossos Centros Cirúrgicos costumam contar com poucos enfermeiros (às vezes só um) e muitos atendentes, apesar de existirem já hospitais que contam com uma alocação de recursos humanos de enfermagem no C.C., semelhante à apresentada para o Hospital em geral (por exemplo Hospital das Clínicas da Faculdade de Medicina do USP: $64,4 \%$ atendentes, $15,8 \%$ auxiliares de enfermagem e $19,8 \%$ de enfermeiro).

Com relação a essa alocação de pessoal de enfermagem, no Brasil, em São Paulo, e no C.C., chama a atenção a disparidade entre os hospitais públicos e privados, evidenciando a política capitalista de absorção de mão-de-obra desqualificadas, uma vez que ela é mais barata, bem como a inexistência de padrões de quadro de pessoal consequiente a uma política nacional de recursos humanos nesta área, o que denota uma falta de valorização e de preocupação maior com a qualidade da assistência de enfermagem prestada, pois se incentiva o desempenho de atividades de enfermagem por pessoal sem preparo formal.

Nesta linha de raciocínio, analisando os dados apresentados pelo levantamento realizado pelo COFEn ${ }^{5}$ e os da nossa observação nos C.C. do Estado de São Paulo, verifica-se que quanto menor o número de leitos e de salas de operações, maior a deficiência quantitativa de enfermeiros e que, à medida que aumenta o número de leitos e de Salas de Operações (S.O.), cresce muito mais o número de "pessoal auxiliar" do que de enfermeiros. Esta situação evidencia, mais uma vez, uma coerência com a política capitalista de recursos humanos na área da saúde e, especificamente, em relação à Enfermagem: as "macroempresas" têm maior necessidade de pessoal em nivel de "gerência" denotando a ideologia institucional que percebe o enfermeiro como o elemento intermediário entre o administrador e o trabalhador, muito mais do que um prestador de assistência direta de enfermagem.

Nesse sentido, é interessante salientar que o exercício profissional, concretizado pela prática, resume o significado de qualquer profissão na sociedade. Subsiste, na prática do enfermeiro (e da enfermagem), uma grande distância entre o "saber" e o "fazer", ou seja, entre a "Teoria" e a "Prática, denotando que nosso exercício profissional não se reveste da qualificação de uma práxis"; se assim fosse, ela demandaria um modo de agir no qual o agente, a ação e o produto seriam partes intrinsicamente ligadas e interdependentes, não sendo possível separá-los, ou seja, o "agir/fazer" seria resultante de um processo de vai-e-vem entre prática-reflexão-teoria-reflexão ${ }^{23}$.

O entendimento desta caracteristica profissional como conseqüência não de posturas e atitudes individuais, mas da relação de forças sociais (econômicas, políticas e ideológicas) do setor saúde com a sociedade, é de vital importância a fim de que tais forças não sejam entendidas como produto de nossos desejos, intenções individuais, mas sim como conseqüência do desenvolvimento das forças produtivas do modo de produção vigente. Este rejeita a unidade entre teoria e prática, dico- 
tomia esta explicitamente concretizada desde os primeiros niveis da formação formal brasileira: a Escola Capitalista é já um produto da divisão entre trabalho intelectual/manual, o que reafirma a dissociação teoria/prática da educação brasileira, de modo geral, não considera a concretudade de nossa sociedade dividida em classes sociais antagônicas. Ela "vê" o homem como que isolado, liberado de sua determinação e os seus objetivos expressam a visão de mundo da classe dominante e levam à inculcação, pelos estudantes, desses valores. O modelo de Homem proposto é o Homem-universal de essência do Idealismo, é o burguês liberal, a-histórico e idealista, e os valores, tais como são apresentados, afastam a possibilidade de compreensão objetiva da realidade.

Do ponto de vista do VALOR da força de trabalho na Enfermagem, o estudo do COFEn ${ }^{5}$ comprova o quanto a categoria é explorada. Partindo-se do conceito de que "o valor da força de trabalho é igual ao valor de todos os produtos necessários para sua conservação e reprodução em uma dada sociedade" ", nesse valor é preciso considerar: as necessidades básicas do trabalhador e de sua família; as necessidades culturais e os níveis de especialização. Esta "especialização" refere-se ao tempo de trabalho socialmente necessário que foi despendido durante o aprendizado de sua especialização, bem como as necessidades de conservação e elevação de seu nivel ?

Baseando-se no "salário mínimo real" corresponde ao "salário necessário para assegurar ao trabalhador e sua familia as condições mínimas de sobrevivência estabelecida pela Constituição brasileira" 7 estabelecido pelo DIEESE, para setembro de 1984, verificou-se que $75,3 \%$ dos enfermeiros, $91,4 \%$ dos técnicos, $84,2 \%$ dos auxiliares e $90,1 \%$ dos atendentes de enfermagem não ganham o equivalente a 1 (um) mínimo real".

As reflexões aqui resumidas, ainda que parciais, encaminham à conclusão da necessidade de que esse componente do trabalho do enfermeiro - o trabalho e a força de trabalho do enfermeiro de C.C. seja entendido como histórico e socialmente determinado e de que toda e qualquer transformação terá que, necessariamente, levar em consideração esta determinação.

SEGUNDO ELEMENTO ESSENCIAL DO TRABALHO - o objeto de trabalho do enfermeiro de C.C., (e da Enfermagem).

Pensar o objeto de trabalho do enfermeiro de C.C. e da Enfermagem indica uma perspectiva de análise do trabalho deste profissional que evidencia muitas contradições, não só devido a idealizações teóricas, mas também devido a polarizações da prática.

Vários trabalhos de colegas enfermeiras, através da compreensão das vinculações da prática da Enfermagem com as determinações emanadas da estrutura social ajudaram no desvendamento desse "objeto" $1,3,12,13,17,19,22$. Segundo alguns destes estudos existem dois momentos distintos na construção da prática da Enfermagem: a que se organiza antes do capitalismo europeu e aquela que nasceu com o capitalismo. 
A Enfermagem no pré-capitalismo foi uma atividade sem vinculações com a atenção médica e configurou-se como uma ocupação socialmente desvalorizada, feminina, centrada no cuidado direto caritativo e exercida por religiosos e/ou leigos analfabetos e tidos como "imcrais" e, assim sendo, com conotações conflitantes: por um lado de abnegação, caridade e meiguice e, por outro, de trabalho tido como imoral, sujo, de pessoas vulgares e desonestas.

As profundas mudanças conseqüentes à Revolução Industrial e à consolidação do modo de produção do capitalismo geraram uma nova representação do "objeto" da saúde e das "finalidades" das "práticas de saúde" e alteraram a posição social de seus agentes, as condições e os instrumentos de trabalho. A grande forma de controle da classe trabalhadora necessária ao desenvolvimento industrial e ao "exércíto de reserva" foi a "manipulação do corpo" enquanto "instrumento de trabalho". As práticas de saúde absorveram esta ideologia capitalista dominante e se dirigiram no sentido de implementar intervenções que promovessem a manutenção/elevação dessa "força de trabalho", o que, por sua vez, legitimava a hegemonia de classe (burguesia como classe que dominava a concepção do processo de trabalho) e as relações de dominação/subordinação (trabalho intelectual/manual).

Conseqüentemente a estas transformações ocorre a institucionalização da Enfermagem enquanto profissão, não mais para ser executada por "leigos despreparados" e por religiosos, mas como uma atividade que, a partir de então, exigiria "preparo técnico", e cujo espaço foi o "Hospital", transformado agora (séc. XVIII) em local de prática e ensino da Medicina.

Esta "Enfermagem Moderna", que se instala na Inglaterra a partir de 1860 sob a liderança de Florence Nightingale e consolida, em definitivo, uma transformação histórica na profissão: coerente com os já nitidos contornos da separação de classes sociais e com marcante influência militar, distancia irremediavelmente o "pensar" e o "fazer" e evidencia o nascimento do trabalho assalariado da Enfermagem, sob o modo de produção capitalista.

O "objeto de trabalho" da Enfermagem no Sistema Nightingale era o "corpo", privilegiando-se o "conforto à alma". A partir ciai, passa a ser valorizado o "corpo biológico" com intervenção de enfermagem aderentes às "ciências naturais". A partir do séc. XX, desenvolve-se mais a direção técnica do trabalho, principalmente nos EEUU, surgindo outros agentes para exercê-la. O enfermeiro continuará a se caracterizar como tendo um trabalho "mais intelectual" em relação a esses agentes, mas agora sempre subordinado ao médico, e na prática da Enfermagem ocorrerão as mesmas articulações do campo da saúde em geral: a articulação infra-estrutural a fim de racionalizar e potencializar o trabalho médico no cuidado direto ao paciente (exercido pelos "demais agentes" subordinados ao enfermeiro) ou em atividades de supervisão e administração desse cuidado (desenvolvidas pelo enfermei- 
ro) e a articulação super-estrutural, a fim de reproduzir, pela legitimação, a hegemonia e o modelo social de dominação/subordinação, principalmente através das ações de supervisão e controle. Coube ao enfermeiro, portanto, em sua área de atuação, as relações inerentes ao modo de produção capitalista, contribuindo assim para a manutenção da sociedade de classes.

$\mathrm{O}$ avanço de tecnologia médica e hospitalar faz com que atividades, até então da alçada do médico, passem a constituir-se em tarefas do enfermeiro e o Hospital começa a assalariar enfermeiros para "treinar" e "supervisionar" o trabalho de um pessoal de enfermagem que cada vez tem menor preparo formal prévio: a expectativa não era "dar assistência de enfermagem" mas sim "dar conta" da grande demanda dos cuidados médico-delegados e dos originados pela internação dos pacientes nos hospitais.

A Enfermagem institucionalizada no Brasil surge na década de 20 (Esc. Ana Néri 1922/23), 63 anos após seu surgimento na Inglaterra e quase um século após a organização do ensino médico brasileiro. Sua implantação esteve atrelada ao modelo americano "nightingeliano" e, por isso, abrigou desde o início grandes contradiçōes internas devido às diferenças culturais e de necessidades de atenção, bem como às contradições inerentes à sua inserção no modo de produção capitalista brasileiro.

O dia-a-dia do trabalho do enfermeiro de C.C. está, sem dúvida nenhuma, condicionado histórica e socialmente, bem como a visão que têm de sua própria atividade, sua concepção de sociedade, de Homem, do processo saúde-doença e de Enfermagem, uma vez que sua consciência é alimentada por idéias, valores, preconceitos, juízos, etc. vigentes na sociedade como um todo.

A grande influência da tendência idealista na visão de mundo das enfermeiras brasileiras, apesar de subordinada às necessidades de reprodução das condições em que se dá sua prática (capitalismo dependente), guarda um ritmo próprio já que a determinação interna se dá muito menos por sua inserção como "sujeito" do processo de determinação e muito mais à incipiente "praxis" reflexiva do enfermeiro e da categoria como um todo. Essa incipiente "praxis" reflexiva tem tido como produto a acomodação do enfermeiro (e da enfermagem) em relação à sua situação na estrutura de produção de serviços e na estrutura de poder das Instituições de assistência à saúde, às limitações de seu "saber" e "dominio de conhecimento" e à legitimação de seu campo de trabalho.

$\mathrm{Na}$ análise da prática concreta dos enfermeiros de C.C., ficam evidenciadas as influências do Idealismo humanista cristão enquanto expectativas percebidas e sentidas, pelo próprio enfermeiro, pela Instituição, pela categoria médica e pelo aparelho formador, de obediência, respeito à hierarquia, de humildade, espírito de serviço, abnegação, de não contestador e, portanto, que não exerce crítica. 
Quando o enfermeiro de Centro Cirúrgico declara, por exemplo, que "o enfermeiro, para o médico, e também muitas vezes para o funcionário, tem que ser "bonzinho", "obediente", "deve respeitar o médico como o "dono" do paciente, "não deve questionar", mas, ao mesmo tempo, "deve deixar tudo em ordem, saber o que está acontecendo e, ainda, "mandar" nos "demais agentes" e "cobrar o trabalho destes funcionários", ele evidencia que a formação do recurso humano na área da Enfermagem, atende de modo geral, à expectativa da classe cominante que procura, de um lado, um trabalho com determinada qualificação, em relação ao qual será exigida certa capacidade de iniciativa, de decisão e de assunção de responsabilidade a fim de responder ao progresso tecnológico dos meios de produção e organização do trabalho; mas por outro lado, também serão tomadas precauções a fim de que não alimente ambições desmedidas, nem tente competir com a Autoridade/Poder institucionalizado (administração institucional/saber médico) ${ }^{9}$.

A influência do "Modelo Religioso" na representação do enfermeiro brasileiro traz também como produto o enfrentamento de sérios problemas trabalhistas consequentes a uma organização política e sindical frágil - inexistência de piso salarial, de sistema de benefícios sociais congruentes com os riscos físicos e psíquicos comuns ao seu ambiente de trabalho, jornada longa de trabalho, etc.

As influências do Iidealismo humanista liberal evidenciaram-se nas intervenções de enfermagem como atividades instituidas ao interior da prática médica c dependente de sua autoridade racional (saber), do seu marco conceitual (principalmente de Homem-paciente e de processo saúde-doença) tanto quanto de suas prescriçōes e isto é identificado em declarações de enfermeiros de C.C. tais como: "percebo que o enfermeiro é só "cumpridor de normas", enquanto que o médico é o "ditador das normas"; "o paciente não é visto como o foco principal da assistência não só pela equipe médica, mas também, devido ao acúmulo de atribuições burocráticas e administrativas, pela equipe de enfermagem"; "a enfermeira, na área de recepção do paciente C.C., fica pressionada pelo cirurgião/anestesista que, muitas vezes, não deixa que ela desenvolva 0 procedimento de "recepção do paciente no C.C." por que isto vai fazer" com que haja uma "demora" no encaminhamento do paciente e ele (cirurgião/anestesista) não pode esperar".

Apesar desta já, largamente, "aceita" dependência da Enfermagem à autoridade médica, evidencia-se ainda com pouca transparência em relação ao fato de que o "objeto de trabalho" do enfermeiro, na passagem da "Enfermagem Tradicional" para a "Moderna" transformou-se (sendo, inclusive que, no Brasil, a institucionalização foi já da Enfermagem Moderna e, portanto, de ser "objeto" já transformado); a grande maioria dos enfermeiros, além dos auxiliares, técnicos e atendentes de enfermagem e dos médicos, continua a identificar, no nivel de "idealização", o desempenho do enfermeiro com o "cuidado direto", ou seja, com a Enfermagem do "enfermeiro" que existia no capitalismo europeu, Enfermagem esta que não apresentava a divisão técnica entre "cuidado 

agentes.

Nesta linha de reflexão sobre o "objeto de trabalho" da Enfermagem de C.C. brasileira, é interessante salientar que desde sempre o seu "objeto" foi diferenciado de acordo com o tipo de categoria de pessoal: o enfermeiro tendo, prioritariamente, como "objeto de trabalho" as "atividades gerenciais" e de "ensino" enquanto "atividades intelectuais" e de "concepção", e os "demais agentes" enquanto "circulantes de S.O.", as atividades "manuais" e de "execução", enquanto "cuidados diretos" na S.O. e implementação de decisões tomadas pelo enfermeiro ou por ele mediadas.

O trabalho da Enfermagem em Centro Cirúrgico, igualmente a qualquer outra área hospitalar, sob o ponto de vista das relações técnicas, de produção, é um processo desenvolvido por vários agentes e, assim sendo, è um "trabalho cooperativo" e seus agentes, do ponto de vista das "relações sociais de produção", são trabalhadores não proprietários dos meios de produção (assalariados do capital privado ou do Estado). O enfermeiro de Centro Cirúrgico, tendo como "objeto de trabalho" a função gerencial, evidencia-se, no contexto desse trabalho cooperativo, como trabalhador indireto, isto é, como o elemento que assume a necessária função de "direção" e "coordenação" das atividades parcelares individuais do trabalho coletivo. Isto posto, fica mais transparente que a forma de assalariamento do enfermeiro é determinada pelo fato do "capital" escolhê-lo como "elëmento administrativo" para "representá-lo" no local e, ao representá-lo no local: "supervisionar" e "organizar" o trabalho da Enfermagem a fim de potencializar o "processo de terapêutica anestésico-cimúrgica". Identifica-se, ainda, a função do enfermeiro de Centro Cirúrgico no "controle do rendimento do trabalho da Enfermagem", numa perspectiva de "fiscalizador do processo de produção assistência médica", haja vistas suas atribuições de "previsão, provisão e controle dos recursos humanos" e de "supervisão de pessoal", sendo que, por exemplo, o cálculo de pessoal é realizado na sua grande maioria, a partir da capacidade da assistência médica $\left(\mathrm{n}^{\circ}\right.$ de S.O., estatística mensal das cirurgias, necessidade de provimento de material de consumo e especializado, etc.) e não de um padrão de qualidade proposto de assistência de enfermagem perioperatória.

As expectativas administrativas (institucionais e médicas) rarissimas vezes são relativas à "coordenação da assistência de enfermagem perioperatória", mas sim relativas ao "controle gerencial e burocrático" de toda a Unidade do C.C.. O alcance de tais expectativas requer a dedicação de grande parte do tempo e da energia do enfermeiro de C.C., em direção à consecução de atribuições/tarefas esperadas e ditadas pela estrutura organizacional técnico-pragmática e burocrática de nossos Hospitais e que se referem não a "um saber específico do profissional", mas "à previsão, provisão e controle de recursos humanos e materiais", para o cirurgião/anestesista e para a Instituição, muito mais do que para o cliente. A "autoridade" da maioria das condutas de enfermagem (do enfermeiro e dos "demais agentes") provêem do cirurgião/anestesista - 
por meio de prescrições, ou da Instituição - por meio de "Normas" e "Rotinas", características essa do "trabalho" do enfermeiro (e da Enfermagem) que evidencia, mais uma vez, sua posição de "trabalhador indireto" no contexto da assistência institucional hospitalar brasileira.

A assistência de enfermagem perioperatória é facilmente evidenciada como não sendo um "valor de uso" que "pode ser enviado ao mercado para intercâmbio direto com outras mercadorias", mas sim como sendo "uma parte do produto final - assistência médica (cirúrgica e anestésica) -, a qual, por sua vez é atribuido um "valor de uso" permutável no mercado.

Neste aspecto do "objeto de trabalho" do enfermeiro (e da Enfermagem), o mais importante é ressaltar que a divisão de trabalho na Enfermagem de C.C. não se resume spenas à funções/tarefas "divididas tecnicamente", mas sim, "atribuidas a diferentes classes de trabalhadores". Nesta divisão se deixa transparente que a diferenciação de objetos de trabalho não se relaciona a uma divisão do trabalho de Enfermagem em seus elementos constituintes, mas sim está relacionada à criação do trabalho parcelado e que essa divisão promove (e permite), a alienação do trabalhador, o aumento da produtividade com vistas à potencialização da assistência médica e o barateamento das parcelas individuais de trabalho.

Assim sendo, conclui-se que a divisão de trabalho na Enfermagem de C.C. de acordo com o grau de qualificação de seus agentes - enfermeiros, auxiliares e atendentes - está subordinada e é determinada pela divisão social do trabalho e se reflete na divisão trabalho manual/ intelectual entre pessoas de classes sociais diferentes, ou seja, não é somente (e prioritariamente) a "complexiảde do saber" que define a divisão, mas lá, é sim, comandada por uma divisão técnica subordinada às relações de produção da sociedade brasileira. Isto faz emergir a contradição fundamental do elemento "objeto de trabalho" da Enfermagem brasileira em C.C. - a contradição cuidado direto/indireto - enquanto produto das relações sociais de produção que têm como determinante a contradição fundamental da socicdade brasileira - a contradição Capital/Trabalho.

TERCEIRO EILEMENTO ESSENCIAL DO TRABALHO - o instrumental de trabalho do enfermeiro de C.C. (e da Enfermagem).

Esta perspectiva de análise do "trabalho" possibilita evidenciar o tipo de relação que se estabelece entre o enfermeiro de C.C. e "os meios de produção". A partir da visão do materialismo histórico-dialético, os "meios de trabalho" não são produzidos "a priori", mas sim são produto da prática social e, assim sendo, são históricos e socialmente determinados.

A prática da Enfermagem no C.C. (e o "trabalho" do enfermeiro de C.C., embasada no modelo funcionalista permeado por uma praxis reiterativa e imitativa, evidencia-se principalmente nas suas atividades técnico-burocráticas, denotando só traços tênues de intencionalidades no 
exercício profissional e de transformação/criação, bem como marcante influência do Idealismo técnico-pragmático.

Como parte do seu desenvolvimento histórico, enquanto instrumento de trabalho, o "saber" da Enfermagem no Brasil nestas duas últimas décadas está permeado de tentativas mais ou menos evidentes de "sistematização da assistência de enfermagem", sendo que este "cuidado planejado", na maioria das vezes, não passa de um instrumento teórico que o enfermeiro lança mão para tentar se apropriar do objeto de trabalho da Enfermagem como um todo, pelo planejamento e controle de cada fase do processo de assistência, inclusive o seu modo de execução, o que, mais uma vez, corresponde a uma divisão entre trabalho intelectual e manual.

A "dimensão intelectual" do trabalho da Enfermagem é utilizada para o estabelecimento de uma proposta definitiva de "autonomia" do enfermeiro dentro da pretensamente denominada "equipe de enfermagem". A proposta para aclarar os conflitos da prática da Enfermagem brasileira - em geral e no C.C., concretizados por questões tais como "qual é o papel do enfermeiro e dos demais agentes?; "qual é o tipo e a extensão de sua autonomia no confronto com as outras práticas de assistència à saúde? "qual é seu corpo de conhecimento específico?", é direcionada muito mais à "intelectualização" do Enfermeiro. Esta, mais uma vez, está predominantemente atrelada e dependente da produção cientifica norte-americana e, assim, não objetiva e não promove uma reflexão conjunta de todos os agentes da Enfermagem brasileira, reflexão esta dirigida para a utilização dessa abordagem intelectual sistematizada com vistas a superar a dicotomia pensar/fazer por meio de estratégias de planejamento participativo. Neste sentido, estariam envolvidos agentes e clientes da assistência à saúde, o que significaria propor uma ruptura no referencial idealista-técnico-pragmático vigente e a procura de um caminho para estabelecer uma unidade entre Teoria/Prática que confirmasse o Trabalho da Enfermagem como uma "práxis".

$\mathrm{Na}$ Enfermagem de C.C., as tentativas para aclarar o corpo de conhecimentos específicos da categoria são ainda mais incipientes e o que já existe de "sistematização de assistência perioperatória" tem reproduzido a divisão hicrárquica dos "saberes" e dos "fazeres" entre seus agentes e, consequentemente, não tem superado a contradição "cuidado direto/indireto".

A "representação" do cuidado de enfermagem no período do perioperatório é quase que exclusivamente aderente ao "modelo médico-hospitalar", tendo como produto intervenções baseadas no sistema anátomo-fisiológico e na terapêutica médica especializada (cirurgia e anestesia). Neste aspecto, é necessário ressaltar que o tipo de organização prevalente em nossos C.C. (burocrática) quase que impõe que os "pacientes" sejam vistos em termos de diagnóstico e terapêutica médica e que, consequentemente, quando existem formalmente tentativas de captação das reais necessidades de atenção de enfermagem dos pacientes estas sejam desenvolvidas, quase que exclusivamente, a partir destes diagnósticos e propostas de terapêutica médica (cirúrgica e anestésica). 
$\mathrm{Na}$ assistência de enfermagem perioperatória, a dimensão singular, num enfoque de necessidades biológicas do cliente é quase que exclusivamente atendida, uma vez que esse é o padrão da prática médica e assim sendo, é a que tem tido maiores possibilidades de receber elementos cognitivos, atitudinais e psicomotores de intervenções, ou seja, este "modelo" de intervenção, curativa e primordialmente biologizante e no nível do singular, é determinado por elementos ideológicos do modelo de prática de assistência à saúde hegemônico no Brasil - o "modelo médico-hospitalar" para maior elucidação do significado desta dimensão singular, bem como das dimensões particular e estrutural, no contexto da metodologia de assistência de enfermagem consultar QUE'lKO'L \& EGRY ${ }^{10}$.

A persistência da dualidade mentejcorpo nas intervençōes do enfermeiro (e da Eintermagem) de C.C., com a prevalente noçao de que o "social", o "psicossocial" e o "biologico" são esferas interdepencentes mas passiveis de serem atendidas separadamente, oculta a realldade da vida do Homem, "promove o individualismo e a desmobilizaçao, garanundo a permanencia da desigualdade, pois do contrario se racultara a mobilizaçăo ameaçante da comunidade ao compreender que o "socıal" é o determinante dentro destes ures niveis de organızaçao e, consequentemence, o nivel a partir do quai se pode moditicar as conduçoes que perpetuam numa determinada situaçăo"15.

A esse respeito, avaliações oficiais, artigos de publicaçoes em revistas, temas oticials e livres de Eventos da categoria tem alertado que, de modo geral, 0 ensino da Enrermagem, em toaos os niveis, tem propiciado a reproduçäo e continuidade do modelo de assistencia à saude vigente - o médico-hospitalar —, desenvolvendo-se de maneira reaucionısta, com entoque biologizante do processo saúde-doença, organızado por procedimentos e näo voltado para o atendimento da coletıviaade e do Homem em sua totalidade. Consequentemente, estabelecem-se intervençoes com total desarticulação da realidade social e, portanto, com diticulaades para compreender a distribuicaio dos perfis epıaemıologicos e a cuetermmaçäo social do processo saude-aoença, entendiuos como relacioniduos diretamente às condiçoes giopais de vida.

Mesmo a partir deste enfoque reducionista e compartimentalizado, o nivel "psicossocial" é pouco considerado nas intervençóes de entermagem perioperatória. Apesar de existir teoricamente e, mais raramente, na prática, uma énfase bastante acentuada, na Educação em Enntermagem, no "apoio emocional" do paciente, esta intervenção ainda é carente de reais significados concretos, uma vez que o conceito de Homem introjetado pela profissão é o do "Homem universal" e os reais determinantes da afeç̧ão apresentada pelo paciente com proposta de terapêutica cirúrgica são pouco considerados.

Em relação à consideração dos determinantes "sociais" no planejamento da intervenção de enfermagem perioperatória, esta tem ainda grande aderência ao valor idealista, do modelo religioso da Enfermagem Tradicional, de "serviço", de "relacionar-se bem com as pessoas", 
sem que haja a necessária transparência em relação ao fato de que essas determinaçōes correspondem às dimensões particulares e estruturais do processo saúde-doença e que, consequentemente, têm vinculações com as relações de produção, com a estrutura econômica da sociedade brasileira, com a classe social à qual o cliente pertence. Conseqüentemente, não tem como pressuposto que as intervenções do enfermeiro (e da Enfermagem) de C.C. devem considerar a realidade objetiva do paciente cirúrgico e as prioridades de atenção que ele tem para si, requerimentos estes determinados pelo desenvolvimento das forças produtivas e das relações sociais de produção daquele determinado momento histórico.

Em relação às intervenções de enfermagem fundamentadas num corpo de conhecimento específico, há que admitir-se que nas Instituições de Saúde existe "a negação da validade científica de todo outro saber que não seja coerente com a racionalidade do sistema capitalista, a repressão pelos aparelhos legais a todos aqueles agentes que exercem uma prática concorrente ao saber dominante" ${ }^{10}$.

Em relação às características do "objeto de trabalho" do enfermeiro de C.C. na realidade brasileira atual - cuidado indireto enquanto "atividades gerenciais" -, evidencia-se facilmente as influências do "modelo burocrático" oriundo do Idealismo Humanista Liberal, pelo qual a captação da realidade se dá por meio da Razão enquanto "categorias racionais" que dão base ao saber (neste caso, o saber médico) e que paralelamente, privilegia a "consciência individual" como origem absoluta do conhecimento e o "indivíduo" como principal ator de ação ${ }^{21}$.

O não enfrentamento da contradição cuidado direto/indireto no trabalho do enfermeiro de C.C. tem dificultado o "desvendamento" de seu conteúdo real, possibilitando que a ele possa ser atribuído (e "cobrado") qualquer tipo de atividade e, nessa perspectiva, geralmente se "cobra" o que os "outros" não fizeram, situação esta, exemplificada em depoimentos tais como: ". . ficam fazendo o que é dos outros, tapando buraco, juntando os pedacinhos de um e de outro, e o que é "nosso", deixamos de fazer...".

O fato de, neste modelo de administração burocrática, o enfermeiro de C.C. representar a "continuidade de tempo e de lugar e da organização social" "11 não lhe tem atribuído, absolutamente, uma autonomia ou autoridade maior no contexto da assistência hospitalar, uma vez que sua presença é percebida muito mais como de controle (enquanto representação de normas administrativas institlicionais) do que de espaço para intervenções de assistência de enfermagem "direta" ou "administrativa". Neste aspecto, o "ficar responsável por tudo" - a denominada "continuidade de função integrativa e de coordenação" 11 também não the confere autoridade, já que não há relação com a "autoridade racional" enquanto saber específico e já que tal "autoridade" é atribuída ao saber médico, representado por intervenções "clínicas" e não por "controle gerencial".

A ocupação de "cargos administrativos" por enfermeiros no C.C. têm tido, como consequência, na maioria das vezes, que estes se inves- 
tem de autoridade, decorrente do Regulamento e do Regimento da Instituição, através de delegação da Administração Superior, e que ao serem investidos dessa autoridade (administrativa e não técnico-científica), assumirem a responsabilidade inerente, a qual piomove seu compromisso com os objetivos da Institliç̧ão. Assim sendo, eles não somente agem em conformidade com estas Normas mas também, mantêm e buscam tal padronização, e assim, mantêm a burocratização.

O tridimensionamento do compromisso do enfermeiro de C.C. com os valores ideológicos da profíssão (cuidado direto), com a sua atribuição como um dos agentes de mudança e com a estrutura burocrática da organização institucional, gera conflitos e aparentes indefinições, que podem ser entendidos como reprodução das tensões existentes entre a "racionalidade substantiva" e a "racionalidade funcional". A "racionalidade substantiva" refere-se a "um ato de reflexão que revela uma percepção inteligente das inter-relações dos eventos em uma dada situação... ela exige que se dê atenção às finalidades do ato bem como a seu cabedal de conhecimento, o qual vai afetar a maneira como ele compreende e constrói os eventos... envolve uma relativa desreificação da consciência, considerando o mundo social como produto da atividade humana, sujeito a modificação quanto ao significado e a forma" 8 e "... $\mathrm{E}$ exatamente essa postura crítica que faz do homem não o produto, mas um participante crítico de um dado período histórico. A racionalidade substantiva implica o fato que os indivíduos - portadores da razão sejam os "sujeitos" do processo de aprendizagem" 4. E a "racionalidade substantiva" refere-se a "uma série de ações... organizadas de tal forma que conduzam a um objetivo previamente definido, recebendo cada elemento, nessa série de ações, uma posição funcional e um papel... a qualidade da racionalidade funcional é atestada pela condução da ação de modo que a preocupação maior é sobre os meios de realização e a eficiência... como base exclusiva para a ação social, essa forma de racionalidade conduz ao predominio da técnica e a uma extrema reificação do mundo social ... a reificação consiste em considerar que o homem é capaz de esquecer sua própria condição de autor do mundo que o cerca e, mais ainda, que a dialética entre o seu produtor e o seu produto não está conscientizada" 8 .

Não se perde de vista, o fato de que amb os tipos de racionalidade estão sempre presentes na maneira de perceber e elaborar nossa própria visão do mundo; na medida em que prevalece a "racionalidade funcional", a administração organizacional (Institucional, do Serviço de Enfermagem e da Unidade de C.C.) "cada vez mais se transforma em nada mais que uma teoria instrumental, subordinada ao sistema de mercado e dele explicativa. Não há dúvida de que uma teoria organizacional baseada na "racionalidade substantiva" formularia críticas extremamente severas ao comportamento atual das organizações, abrindo novas possibilidades para o aparecimento de modelos alternativos, de novas formas de organização, o que consequentemente poderia fornecer as bases para a reconceituação de nossa sociedade organizacional como um todo" ${ }^{18}$.

A hegemonia do "sistema funcional" é facilmente identificada em nossa prática enquanto ênfase nos meios de realização (procedimentos) 
e na eficiência, sendo sua "intencionalidade" (finalidade) aceita como intrinseca e inquestionável, induzindo, assim, ao existente predominio da técnica no C.C. e à "reificação" do mundo social (de cada um dos agentes, ao nível de vida pessoal, e de todos, ao nivel de ambiente de iiúbalho). Isto significa que há um esquecimento de que o agente da Enfermagem, enquanto Homem, é autor de sua história e que ele se objetiva no seu produto, bem como inexiste estímulo à reflexão crítica em face da realidade da prática e à aprendizagem de habilidades que nos permitam transcender os padrões de comportamento e de exercício prático "sacramentados" pela cultura organizacional burocrática de nossas instituiçōes de saúde.

Nesta linha de análise, é possível ainda evidenciar que não só o "sistema funcional" é hegemônico em nosso saber como instrumento de apreensão e transfornação do nosso objeto de trabalho, mas também que a quase total desconsideração, e até o ocultamento, do "sistema substantivo ou profissional" é produto dos determinantes histórico-sociais dá prática profissional brasileira. Através desta estratégia, se despersondliza o enfermeiro como um dos agentes de enfermagem, bem como a Enfermagem com um dos agentes de saúde, relegando-os (enfermeiro e Enfermagem) a uma posição de insírumento da Organização, com desconsideração à sua capacidade de escolha e interpretação de seu processo de trabalho. Caso houvesse a formalização de espaços para reflexâo, isto significaria a presença de intenções de alterações da composição das fontes de poder enquanto busca de novos caminhos e estratégias para a assisténcia, agora à saúde, e, assim, enquanto assunção do compromisso com a melhoria da qualidade de vida da população brasileira.

\section{PARTE 3 - CONSIDERAÇÕES FINAIS}

As análises aqui portuadas permitem concluir que inexiste uma "indefinição do papel do enfermeiro" na área de prestação de assistència à saúde (médica) no Brasil. Concretamente fica evidenciada a atribuição ao enfermeiro (em geral) de "trabalhador inđireto", bem como o objeto de trabalho "atividades gerenciais e de ensino", enquanto "direção" que harmonize as diferentes atividades individuais (de todos os trabalhadores da instituição - médicos e não-médicos) e que implemente as funções gerais necessárias para que se desenvolva o processo de assistência de enfermagem (processo de cuidado). Esse, por suas características internas, potencializa o processo de assistência médica (processo de cura) sendo uma perspectiva do trabalho do enfermeiro de C.C. (e em geral), a de fiscalizar o processo de produção - assistência médico-cirúrgica e anestésica - enquanto controle da produtividade do trabalho dos agentes da assistência de enfermagem, atribuição que aparentemente se percebe com caráter só técnico, mas que, na sua essência, está sobredeterminada pela função social que o Capital representa.

Fica transparente, também, que a debilidade na identidade profissional do enfermeiro brasileiro é produto das contradições básicas his- 
toricamente determinadas de sua prática - cuidado direto/indireto e autoridade racional-funcional/substantiva - e que a superação dessas contradições se encaminha para a transformação do trabalho do enfermeiro. Essa transformação deve ser mediada por lideranças com visão totalizadora da sociedade, do processo saúde-doença e dos determinantes histórico-sociais, e por um trabalho conjunto entre todas as categorias de agentes da Enfermagem (enfermeiro, técnico, auxiliar e atendente), bem como entre todas as profissões da área da Saúde e, em nenhum momento, descaracterizar a necessidade dessa transformação estar relacionada à transformação na área da assistência à saúde em geral e na formação social da sociedade brasileira.

CASTELLANOS, B.E.P. The operating nurse's work in Brazil (in the eighties). Kev. Lisc. Enf. USP, v. 25, n. 2, p. 177-94, Aug. 1991.

From the view of the historical and dialectic materialism of the nurse work as a social practice insered in the Brasilian capitalistic mode of production of the eighties, these study, through the decomposition of the surgical room nursing work in his three essencial elements, search to point the mecessary comprehension not only of these components but, mainly, for the agreement of his superstructiral relations through the Brazilian mode of production in sense of, with these reflective praxis, search a synthesis, within what I have (what the operating room nurse work is) and, what 1 want, synthesis which will alow a new practice.

UNITERMS: Operating room nursing. Nurses, role.

\section{REFERENCIAS BIBLIOGRAFICAS}

1. ALMEIDA, M.C.P. de; ROCHA, J.C.Y. O saber de onformagem e una dimensito prattica. Såo Paulo, Cortez, 1986.

2. BREILH, J.: GRANDA, E. Investigação da saúde na socledade: cuia pedagócico mobro um novo enfoque do método epidemlol6rico. Sá Paulo, Instituto de Saúde/ ABRASCO, 1986.

3. CASTELLANOS, B.E.P. O trabalho do enfermeiro - procura e o encontro de um caminho para o seu estudo: da abordagem mecanico-funcionalista a pesquisa emancipatória. Sáo Paulo, 1987. 426 b. Tese (Doutorado). Escola de Enfermagem. Universtdade de Săo Paulo.

4. CARAVANTES, C.R. \& PEREIRA, M.J.H. de B. Aprendizagem organtzacional versus estratégia de mudança organizacional planejada: um confronto critico. Rov. Adm. Publ., V. 15, m. 2, p. 23-44, 1981.

5. CONSELHO FEDERAL DE ENFERMAGEM. O exercicio da enfermagem nas Instituiçôes de saúde do Brasil: 1982-83. Rlo de Janeiro. Associaçăo Brasileira de Enfermagem.

6. GerRmano, R.M. Educaçăo e ideologia da enfermagem no Brasil. Săo Paulo, Cortez, 1983.

7. HARNECKER, M. Os conceitos elementares do materialismo histórico. 2 ed. Sáo Paulo. Global, 1983.

8. KIRKHART, L; MEANDES, M.C. Uma avaliação das bases teóricas do desenvolvimento organizacional intelectual. Rev. Adm. Publ., v. 15, n. 1, p. 4-22, 1981.

9. LOYOLA, C.M.D. Os doce(t)s corpo do hospital: as enfermeiras e o poder instituclonal na estrutura hospitalar. Rio de Janeiro, 1984. $137 \mathrm{p}$. Dissertaç⿰丿 (Mestrado) Instituto de Filosofia e Ciencias Suciais, Universidade Federal do Rio de Janeiro. 
10. LUZ, M.T. As Instituiçōes médicas no Brasil: Institulçōes e estratégia de hegemonia. 2 ed. Rlo de Janeiro, Graal, 1879.

11. MAUKSH, H.O. The organizational context of nursing practice. In: Davis, F. The nursing profeesions: live sociological essays. New York, John Willey, 1966. $108-58$.

12. MELO, C.M.M. Divisão gocial do trabalho enfermagem. São Paulo, Cortez, 1986.

13. NAKAMAE, D.D. Bases para o encaminhamento do ensino do enfermagem. Sao Paulo,

14. OFICINA de trabalho: subsidios para a conceituacão da assistência de enfermagem rumo à reforma Sanitária. Brasilia, ABEn/INAMPS, 1987. 12 p. (mimeografado)

15. PROPOSTA de prognama: melhoria da qualidade da assistência de enfermagem no Brasil. Brasilia, CAPES/PAPS/ABEn/CEEN/SESU, 1987. 24 p. (mimeografado) Cortez, 1987 p.

16. QUEIROZ, V.M. de; EGRY, E.Y. Bases metodológicas para a assistência da enfermagem em saúde coletiva, fundamentada no materialismo histórico e dialético. Rev. Bras. Int., v. 41, n. 1, p. 26-33, 1988.

17. RECURsos humanos para a área da saúde no Brasil. Săo Paulo, Fundacăo Getalio Vargas, 1984. p. 371. (Cadernos PROHASA, no 2).

18. RAMOS, A.C. Modelos de homem teoria administrativa. Rev. Adm. Publ. v. 18, n. 2, p. 3-12, 1984.

19. REZENDE, A.L.M. Saúde: dialética do pensar e do tazer. Săo Paulo, Cortez, 1986.

20. SILVA, G.B. Enfermagem profissional brasileira: análise crítica. São Paulo, Cortez, 1886.

21. TRAGTENBERG, M. Burocracia e Ideologia. Sao Paulo, Atica, 1985.

22. TREVISAN, M.A. A função administrativa da enfermeira de instituição hospitalar burocratizada. Ribeiråo Preto, 1986. 200 p. Tese (Doutorado) - Escola de Enfermagem de Ribeirão Preto da Universldade de são Paulo.

23. VASQUEZ, A.S. Fllosofia da praxis. 2 ed. Rio de Janeiro, Paz o Terra, 1977.

24. VINIEGRA, L. Havia um concepto de salud colectiva. Salnd Publ. M6x., v. 27, m. 5, p. $410-8,1985$.

Recebido em 19-3-91

Aprovado em 24-6-91 